\title{
The Influence of Bank Counselors' Experience of Verbal Violence on Self-concept
}

\author{
Sang-Jin Lee ${ }^{1}$ and Ha-Kyun $\mathrm{Kim}^{2} *$ \\ ${ }^{1}$ Doctoral Student, 48513 Graduate School of Information Systems, Pukyong National \\ Univ. Busan, Korea \\ ${ }^{2}$ Professor, 48513 Division of Business, Pukyong National Univ. Busan, Korea \\ ${ }^{1}$ k7121290@hanmail.net, ${ }^{2}$ kimhk@pknu.ac.kr
}

\begin{abstract}
This study is about verbal violence in the course of counseling at banks. Verbal violence is classified as violence in the course of counseling for people who have nothing to do with them. Language violence against irrelevant people is an improvised violence situation in which perpetrators and victims occur in various spaces. It refers to violence committed to others in a certain space. Language violence during the counseling process tends to be neglected due to its unclear substance, but the damage continues to increase. Various psychological studies of actual violence have been conducted in reality, but psychological studies of verbal violence have not been carried out much because they are simply considered. This study focuses on analyzing the relationship of influence on professional self-concepts through the psychological exhaustion of verbal violence experience during the consultation process of banks. The factors that determine the experience of verbal violence are the experience of violence, the experience of violence damage, and the attitude of violence. The collected data were analyzed by Smart PLS 2.0 using structural equations. The summary of the study is as follows. First, the experience of violence has had a significant impact on psychological exhaustion. Second, the experience of violence damage had a significant impact on psychological exhaustion. Third, violent personality had a significant effect on psychological exhaustion. Fourth, psychological exhaustion had a significant impact on professional selfconcepts. In order to solve the problem of overcoming professional self-concepts, differentiated efforts in the experience of violence, violence victimization, and violent attitude are needed in consideration of verbal violence experiences. Related organizations seeking to address verbal violence need to study various opinions on the causes affecting verbal violence behavior.
\end{abstract}

Keywords: Experience of violence offender, Experience of violence victim, Attitude of violence toleration, Psychological exhaustion, Professional self-concept

\section{Introduction}

Lately, verbal violence has caused serious problems in the counseling process due to the development of smart devices of information and communication. The research on verbal violence begins at the call center with the development of smart devices, and a great deal of research is being done as the damage caused by verbal violence is known. There are

Article history:

Received (September 21, 2020), Review Result (October 24, 2020), Accepted (December 9, 2020)

JARR

Copyright (C) 2021 Global Vision Press (GV Press) 
conducted to understand the phenomenon of verbal violence and to identify the causes and to reduce verbal violence. The scope of verbal violence also varies, including definitions, phenomena, types, causes, results, and factors. In the early stages of research on verbal violence, definitions and types were important subjects [1]. In the definition and type of verbal violence study, perpetrators and victims were distinguished from cases of verbal violence.

Verbal violence is classified as violence against people by individuals who are related and are not related [2]. Verbal violence against unrelated persons is an improvised situation of violence between the perpetrator and the victim in various counseling processes. It causes violence against others in the course of counseling through cyberspace and various media. Personal violence in the counseling process tends to be neglected because the substance is not clear, but the damage is continuing, increasing and increasing. Although various psychological studies have been conducted on real violence, verbal violence has been studied in various ways, but there are no studies related to psychological exhaustion and professional self-concept.

In this study, the experience of verbal violence was divided into violence experience, violence victim experience, and violence tolerance. This study was conducted by empirically analyzing that the experience of verbal violence affects professional self-concept through psychological exhaustion. In order to test the relationship between the factors described above, a structural equation model was conducted.

\section{Theoretical background}

\subsection{Experience of verbal violence}

Violence experience is the experience of violence in the counseling process for people. It is conducted a study to prevent the act of violence in the legal or administrative fields [3]. Among the factors of verbal violence, anger is the most important factor among the factors of cyber environment. In terms of verbal violence, the experience of violence and damage caused by verbal violence was studied from various perspectives.

Violence victimization experience is the experience of harming others in cyberspace or in various spaces. Experience of verbal violence victimization is the most important factor predicting experience of verbal violence [4]. Those who have experienced verbal violence are likely to participate in verbal violence.

Violent tolerance refers to an attitude that allows an individual to use violence during counseling. It means that they have an acceptable attitude toward verbal violence without thinking, and the more they do, the more they exercise verbal violence [5]. Therefore, if violence is tolerated in the counseling process, it can change into a violent environment according to the individual's attitude and the situation can change greatly. Violence in counseling is not physical violence but verbal violence, so it is easy to tolerate it.

\subsection{Psychological exhaustion}

Psychological exhaustion refers to psychological wounds caused by violence in the counseling process. Violent tolerance, disdain, and disregard, experienced in the real world, are also problematic in the counseling process. Anti-horse, contempt and disregard create negative feelings for individuals, and they lose control with anger [6]. People who have experienced verbal violence are hurt by their pride, cause anger, experience sad feelings, and become miserable. People who suffer psychological distress from verbal violence often think 
about turnover or suicide. In the psychological study of verbal violence perpetrators, they were told that they would act as a perpetrator by low self-control.

\subsection{Professional self-concept}

The professional self-concept refers to the mental perception of oneself as a professional, especially as a professional, feeling and views on one's work [7]. In other words, it refers to a job in which professionals with considerable knowledge and experience in one field and with high practical skills perform work based on their expertise and make important contributions to society. It is very important for bank counselors to establish a positive professional selfconcept in order to perform their work effectively at the counseling site.

The stronger the post-emotional response, the higher the level of depression, and the lower the level of coping with academic stress, the higher the level of depression. The higher the level of coping with academic stress, the higher the level of professional self-concept, and the higher the level of depression, the lower the professional self-concept. In particular, coping with academic stress and depression were found to have a significant influence on the professional self-concept of nursing college students, and $28 \%$ of the explanatory power of the professional self-concept of nursing college students was found [8]. The professional selfconcept, academic self-efficacy, and major satisfaction of nursing college students showed a positive correlation. It has been verified that is higher. Based on these results, in this study, a program that can promote the professional self-concept is needed because the effect of the professional self-concept of nursing college students on major satisfaction is a major factor [9].

\section{Research model and research hypothesis}

\subsection{Research model}

This study focuses on analyzing the relationship between verbal violence experience and psychological exhaustion and professional self-concept.The factors that determine verbal violence experience were divided into violent violence experience, violence victim experience, and violent tolerance attitude. A research model based on previous research is shown in [Figure 1].

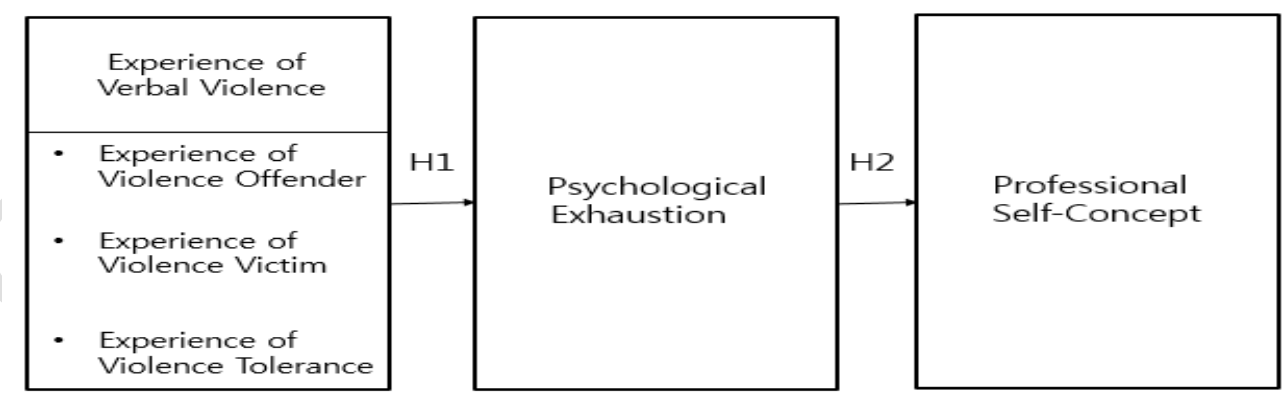

Figure 1. Research model

\subsection{Research hypothesis}

Research was conducted to prevent verbal violence and acts of violence in the legal or administrative sectors. Experience in verbal violence is the most important factor in predicting experience of violence against verbal violence. Violence tolerance refers to an 
unthought-free, acceptable attitude toward verbal violence, and the more verbal violence is exercised in the course of counseling [6]. In this study, the following hypotheses were established based on prior studies.

Hypothesis H1-1; Violence offender will have a significant effect on psychological exhaustion.

Hypothesis H1-2; Violence victim will have a significant effect on psychological exhaustion.

Hypothesis H1-3; Violence tolerance will have a significant effect on psychological exhaustion

Counselors who have experienced verbal violence suffer from self-esteem, cause anger, experience sad feelings, and even become miserable. Professional self-concept has limitations in approaching or solving at the individual level [10] Therefore, in this study, the following hypothesis was established based on previous studies.

Hypothesis H2; Psychological exhaustion will have a significant effect on the professional self-concept.

\section{Empirical analysis}

\subsection{Data analysis method}

A total of 250 users responded to the survey. The basic statistical survey is as follows. $45 \%$ of respondents are male and $55 \%$ are female. Women have a relatively higher proportion than men. In terms of age, the average age was 28.8 years. This is a result of reflecting that most of the respondents are consultants at banks.

It was used to verify the structural model in order to analyze the characteristics of the verbal violence. The question of each constituent concept is very different for the corresponding question. It was composed on the Likert 5-point scale.

For the questionnaire analysis, SPSS 22.0 and Smart PLS 2.0, structural equation software, were used for basic statistics. Concentration validity examines the factor loading value, component reliability (CR) and variance extraction index value (AVE) of each factor. In general, the factor loading value is 0.6 or more, the component reliability value is 0.7 or more, and the variance extraction index value is 0.5 or more. to be. As a result of comparing the square root of the variance extraction index value with the correlation coefficient, the variance extraction index value is greater than the vertical and horizontal correlation coefficient values, so there is no problem with the discriminant validity.

Table 1. Reliability and internal consistency

\begin{tabular}{|c|c|c|c|c|}
\hline Variables & Factor Lodings & AVE & C. R. & Cronbach's $\alpha$ \\
\hline \multirow{4}{*}{ Experience of violence offender } & 0.652 & \multirow{4}{*}{0.700} & \multirow{4}{*}{0.901} & \multirow{4}{*}{0.853} \\
\hline & 0.886 & & & \\
\hline & 0.910 & & & \\
\hline & 0.871 & & & \\
\hline \multirow{2}{*}{ Experience of violence victim } & 0.945 & \multirow{2}{*}{0.906} & \multirow{2}{*}{0.951} & \multirow{2}{*}{0.897} \\
\hline & 0.959 & & & \\
\hline \multirow{2}{*}{ Experience of violence tolerance } & 0.700 & \multirow{2}{*}{0.626} & \multirow{2}{*}{0.823} & \multirow{2}{*}{0.722} \\
\hline & 0.829 & & & \\
\hline
\end{tabular}




\begin{tabular}{|c|c|c|c|c|}
\hline & 0.836 & & & \\
\hline \multirow{4}{*}{ Psychological exhaustion } & 0.925 & \multirow{4}{*}{0.759} & \multirow{4}{*}{0.926} & \multirow{4}{*}{0.893} \\
\hline & 0.894 & & & \\
\hline & 0.834 & & & \\
\hline & 0.827 & & & \\
\hline \multirow{3}{*}{ Professional self-concept } & 0.909 & \multirow{3}{*}{0.850} & \multirow{3}{*}{0.944} & \multirow{3}{*}{0.912} \\
\hline & 0.941 & & & \\
\hline & 0.916 & & & \\
\hline
\end{tabular}

Table 2. Correlation and discriminant validity

\begin{tabular}{|c|c|c|c|c|c|c|}
\hline Variables & AVE & 1 & 2 & 3 & 4 & 5 \\
\hline Experience of violence offender & 0.700 & 0836 & & & & \\
\hline Experience of violence victim & 0.906 & 0.380 & 0.951 & & & \\
\hline Experience of violence tolerance & 0.626 & 0.411 & 0.504 & 0.791 & & \\
\hline Psychological exhaustion & 0.759 & 0.599 & 0.145 & 0.491 & 0.871 & \\
\hline Professional self-concept & 0.850 & 0.631 & 0.246 & 0.623 & 0.702 & 0.921 \\
\hline
\end{tabular}

\subsection{Verification of the structural model}

Smart PLS 2.0 was used for the structural model, and the path coefficient and the coefficient of determination $\left(\mathrm{R}^{2}\right)$ between variables of the research model were derived through the structural model. The coefficient of determination $\left(\mathrm{R}^{2}\right)$ for psychological exhaustion (0.480) and professional self-concept (0.493) was 'high'.

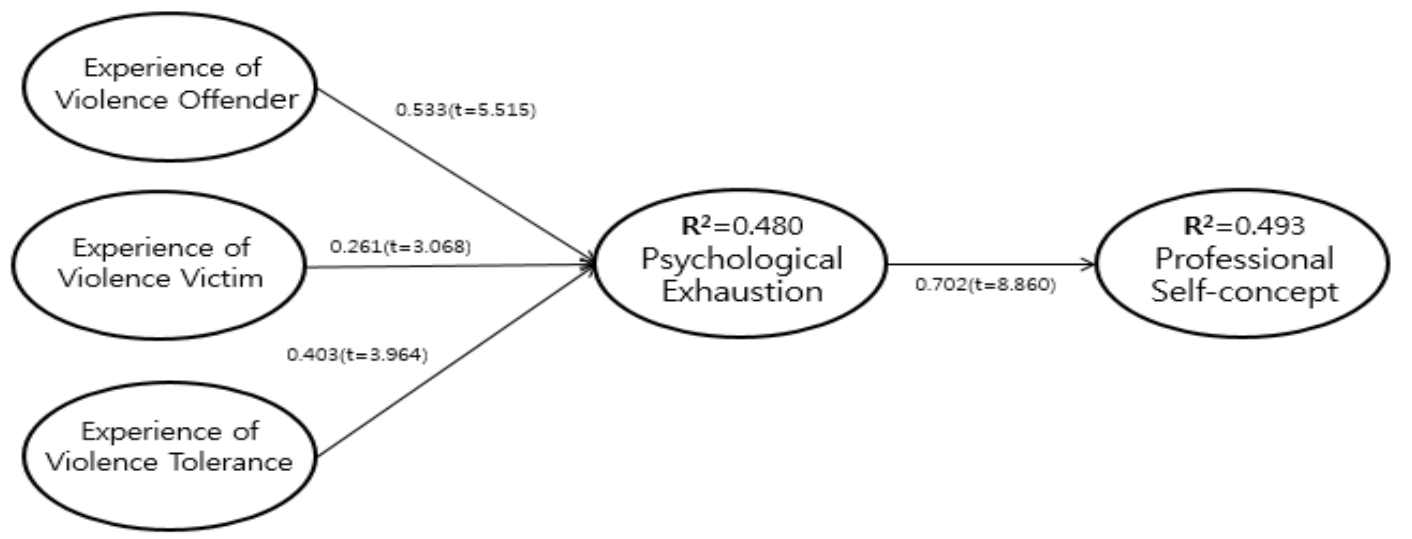

Figure 2. The results of research model

In hypothesis $\mathrm{H} 1-1$, the experience of violence and psychological exhaustion $(\beta=0.533$, $\mathrm{t}=5.515, \mathrm{p}<0.05)$ were found to have a significant effect. This means that there is psychological exhaustion even if there is an experience in verbal violence. The factors for psychological exhaustion of counselors were classified into general life intervention, psychotherapy, vision counseling, and career counseling [3]. It shows the treatment method for psychological exhaustion. There are various opinions on the causes of verbal violence on the violent behavior, but in general, studies are divided into external environmental factors, 
personal factors, and personal behavior factors. In hypothesis H1-2, the experience of violence and psychological exhaustion $(\beta=0.261, \mathrm{t}=3.068, \mathrm{p}<0.05)$ were found to have a significant effect. The experience of violence damage is psychological exhaustion. In the study on the influencing factors of verbal violence [10], the age and environment of the person who committed verbal violence was investigated. This confirmed that the person who commits verbal violence is exposed to the environment of verbal violence and is affected by verbal violence. Hypothesis H1-3's attitude toward violence and psychological exhaustion $(\beta=0.403, t=3.964, p<0.05)$ had a significant effect. The attitude toward violence is that adolescents are psychologically exhausted. It has been studied that verbal violence is exercised as less seriously is taken [6]. Therefore, environmental factors such as violence damage experience, violence experience, violence tolerance, etc. influence psychological exhaustion. Psychological exhaustion and professional self-concept $(\beta=0.702, t=8.860$, $\mathrm{p}<0.05$ ) of hypothesis $\mathrm{H} 3$ were found to have a significant effect. It is that psychological exhaustion affects the professional self-concept.

Table 3. Hypotheses testing results

\begin{tabular}{|c|c|c|c|}
\hline Hypotheses Path & Coefficient $(\beta)$ & t-value & Result \\
\hline H1.1: Experience of violence offender $\rightarrow$ Psychological exhaustion & 0.533 & 5.515 & Accept \\
\hline H1.2: Experience of violence victim $\rightarrow$ Psychological exhaustion & 0.261 & 3.068 & Accept \\
\hline H1.3: Experience of violence tolerance $\rightarrow$ Psychological exhaustion & 0.403 & 3.964 & Accept \\
\hline H2: Psychological exhaustion $\rightarrow$ Professional self-concept & 0.702 & 8.860 & Accept \\
\hline$t=1.97^{*}, p<0.05$ & &
\end{tabular}

$t=1.97^{*}, p<0.05$

\section{Conclusion}

In this study, the experience of verbal violence has been proven in psychological exhaustion and professional self-concepts: First, the experience of violence has had a significant impact on psychological exhaustion. Second, the experience of violence damage had a significant impact on psychological exhaustion. Third, violent personality had a significant effect on psychological exhaustion. Fourth, psychological exhaustion had a significant impact on professional self-concepts.

The empirical studies of psychological exhaustion and professional self-concepts due to experience in verbal violence have been identified as follows. The following implications may be presented to relevant organizations concerned with verbal violence during the consultation process. First, to solve the problem of overcoming professional self-concepts, it differentiated efforts in the experience of violence, violence victimization, and violent attitude are needed in consideration of verbal violence experiences. Related organizations seeking to address verbal violence need to study various opinions on the causes affecting verbal violence behavior. In general, it is divided into external environmental factors, individual internal factors, and individual behavioral factors, but detailed research is required. Second, experience of violence, experience of violence damage, experience of violence damage, and attitude of violence were found to affect psychological exhaustion. Third, in order to improve the professional self-concept in the field of bank counseling, it is absolutely necessary to 
prepare detailed strategies to increase the level of coping with stress related to banking and to reduce the feelings of depression of bank counselors. In order to control the depressive feelings, appropriate therapeutic intervention for the emotional response of the bank counselor after the related verbal violence experience may be helpful.

\section{References}

[1] Y. Chung and K. Du, "Review paper about causes, effects and intervention of adolescent cyberbullying from the preventive counseling perspective,” Korean Journal of Youth Studies, vol.21, no.8, pp.373-406, (2014)

[2] K. Ryu, J. Park, Y. Kim, D. Lee and W. Kim, "Development of ai-based real time agent advisor system on call center; focused on $\mathrm{n}$ bank call center," Korea Academy Industrial Cooperation Society, vol.2, pp.750762, (2019)

[3] B. E. Wampold, J. W. Lichtenberg and C., "A. Daehler, principles of empirically supported interventions in counseling psychology," The Counseling Psychologist, vol.30, no.2, pp.192-217, (2012)

[4] C. Lee, N. Sin and B. Ha, "A study on the situation of youth cyberbullying and measures to prevent it," Korea Institute for Youth Development Report, pp.1-268, (2014)

[5] Y. Choi, "A study on the function of the business of banking in banking act," Law Revies, vol.11, pp. 77112, (2020)

[6] K. R. Williams and N. G. Guerra, "Prevalence and predictors of internet bullying, journal of adolescent health," vol.41, pp.14-21, (2007)

[7] D. Arthur, "Measurement of the professional self-concept of nurses: Developing a measurement instrument, nurse education today," vol.15, no.0, pp.328-335, (1995)

[8] H. O. Jeon, "The effects of verbal violence in clinical practice, academic stress coping, and depression on professional self-concepts among Korean nursing students," Journal of Korea Academy Industrial Cooperation Society, vol.19, no.8, pp.501-512, (2018)

[9] K. M. Yang, "The relationship among professional self-concept, academic self-efficacy and major satisfaction in nursing students," Journal of Digital Convergence, vol.15, no.12, pp.445-453, (2018)

[10] K. Kim, "Toward a science of prevention counseling," Journal of Asia Pacific Counseling, vol.1, no.1, pp.13-28, (2011) 
The Influence of Bank Counselors' Experience of Verbal Violence on Self-concept

This page is empty by intention. 